\title{
Worse Preoperative Status Based on Inflammation and Host Immunity Is a Risk Factor for Surgical Site Infections in Colorectal Cancer Surgery
}

\author{
Masano Sagawa ${ }^{1}, K^{2}$ azuhiko Yoshimatsu' ${ }^{1}$, Hajime Yokomizo', Yuki Yano', \\ Sachiyo Okayama ${ }^{1}$, Takebumi Usui ${ }^{1}$, Kentaro Yamaguchi ${ }^{1}$, Shunichi Shiozawa ${ }^{1}$, \\ Takeshi Shimakawa ${ }^{1}$, Takao Katsube ${ }^{1}$, Hiroyuki Kato ${ }^{2}$ and Yoshihiko Naritaka ${ }^{1}$ \\ ${ }^{1}$ Department of Surgery, Tokyo Women's Medical University Medical Center East, Tokyo, Japan \\ ${ }^{2}$ Department of Clinical Laboratory, Tokyo Women's Medical University Medical Center East, Tokyo, Japan
}

\begin{abstract}
Objective: The modified Glasgow Prognostic Score (mGPS) is an inflammation-based measure of malnutrition that reflects a state of cachexia in cancer patients. We evaluated mGPS as an index to predict surgical site infection (SSI) incidence in patients undergoing colorectal cancer surgery.
\end{abstract}

Subjects and Methods: We retrospectively analyzed 351 patients who underwent colon cancer resection. Factors correlated with the incidence of SSIs were identified by logistic analysis and stepwise selection.

Results: SSIs were observed in 32 patients, with an incidence of 9.1\%. Univariate logistic analysis revealed mGPS (Score 2), laparotomy, resection of other organs, colostomy, excessive blood loss ( $>423$ $\mathrm{mL}$ ), long duration of surgery (>279 minutes), pulmonary dysfunction, prognostic nutritional index $(\mathrm{PNI}) \leq 40$, neutrophil lymphocyte ratio $(\mathrm{NLR})(>4)$, and controlling nutritional status (CONUT) $\geq 2$ to be associated with an increased incidence of SSIs. Multivariate analysis with variables selected by the stepwise procedure also revealed mGPS (Score 2) (Odds ratio (OR)=3.55, 95\% Confidence interval (CI) $1.30-$ 9.56; $\mathrm{p}=0.01$ ), colostomy ( $\mathrm{OR}=6.56,95 \% \mathrm{CI} 1.60-31.38 ; \mathrm{p}=0.01)$, excessive blood loss $(\mathrm{OR}=3.20,95 \% \mathrm{CI}$ 1.23-8.42; $\mathrm{p}=0.02)$, and NLR $(>4)(\mathrm{OR}=3.24,95 \% \mathrm{CI} 1.31-8.17 ; \mathrm{p}=0.01)$ to be independent risk factors.

Conclusion: mGPS is an independent risk factor for SSIs. Our results suggest that cachexia before surgery in patients with colorectal cancer might predict the incidence of SSIs.

(J Nippon Med Sch 2017; 84: 224-230)

Key words: modified Glasgow Prognostic Score (mGPS), surgical site infection (SSI), colorectal cancer surgery

\section{Introduction}

Cancer cachexia is a complex metabolic abnormality syndrome characterized by skeletal muscle atrophy occurring regardless of loss of body fat mass ${ }^{1}$. In cancer tissue, IL-6 is produced, tumor-host interactions occur, systemic metabolic abnormalities are induced, and cancer-induced weight loss (CIWL) owing mainly to skeletal muscle atrophy occurs ${ }^{2}$. This systemic metabolic abnormality reflects the pathology of cancer cachexia ${ }^{2}$.

C-reactive protein concentration (CRP) is induced by IL-6 in the liver, and objectively represents the actual nature of cancer cachexia ${ }^{3}$. CRP correlates with IL-6 and se- rum albumin $(\mathrm{Alb})$ is inversely correlated with $\mathrm{CRP}^{4}$. The modified Glasgow Prognostic Score (mGPS) is classified by CRP and Alb, and is an indicator of inflammationbased nutritional disorders ${ }^{4}$. mGPS also correlates with muscle atrophy and CIWL ${ }^{4}$, and is frequently used as an indicator of cachexia ${ }^{5}$. mGPS is divided into three groups by score (Score $0-2)$, with a score of 2 (CRP $>1.0 \mathrm{mg} / \mathrm{dL}$ and $\mathrm{Alb}<3.5 \mathrm{~g} / \mathrm{dL})$ reflecting cachexia ${ }^{6}$.

Cachexia is observed in the early phase of diagnosis in $10-20 \%$ of colorectal cancer patients ${ }^{7}$. Moreover, cachexia accompanied by a systemic inflammatory response following invasive surgery reportedly induces postoperative

Correspondence to Kazuhiko Yoshimatsu, MD, PhD, Department of Surgery, Tokyo Women's Medical University Medical Center East, 2-1-10 Nishiogu, Arakawa-ku, Tokyo 116-8567, Japan

E-mail: kyoshsu@dnh.twmu.ac.jp

Journal Website (http://www2.nms.ac.jp/jnms/) 
infectious complications ${ }^{7}$. Infectious complications are classified as surgical site infections (SSIs) and remote infections (RIs) ${ }^{8}$. Adaptive measures and elucidation of risk factors for SSIs are important because their incidence is high, and since patients with SSIs tend to be in a serious condition'. To our knowledge, only a few reports have examined the relationship between mGPS and SSIs ${ }^{10,11}$. Accordingly, we examined factors that affect SSI incidence in colorectal cancer surgery, with a particular focus on cachexia using mGPS as an index.

\section{Methods}

\section{Subjects}

A total of 351 patients who underwent colorectal surgery between January 2005 and December 2008 were enrolled for analysis. Subjects were those who underwent colon cancer resection with anastomosis. Those who underwent colon cancer resection without anastomosis were excluded. The study population did not include patients who underwent surgery for benign disease.

\section{Informed Consent}

We followed the retrospective observational research information disclosure procedure (opt-out) of Tokyo Women's Medical University for obtaining informed consent from research subjects. This study was approved by the Ethics Committee of Tokyo Women's Medical University (No. 4150).

\section{Methods}

We analyzed clinicopathological factors associated with SSIs, categorized as follows: mGPS (Score $0 \cdot 1$ /Score 2 ), sex (male/female), age $(\geq 75 /<75$ years), depth of tumor invasion( $\leq \mathrm{MP} / \geq \mathrm{SS}$ ), approach (laparotomy/laparoscopy), location (colon/rectum), resection of other organs (yes/ no), colostomy (yes/no), timing of operation (emergency/elective), blood loss (large/small), duration of surgery (long/short), histology (tub1, 2/others), ileus (yes/ no), diabetes mellitus (yes/no), pulmonary dysfunction (yes/no), performance status $(0 / \geq 1)$, American Society of Anesthesiologists classification (ASA) $(1 \cdot 2 / 3)$, body mass index $(\mathrm{BMI})(<18.5 / \geq 25.0)$, prognostic nutritional in$\operatorname{dex}(\mathrm{PNI})(\leq 40 />40)$, neutrophil lymphocyte ratio $(\mathrm{NLR})$ $(>4 / \leq 4)$, controlling nutritional status (CONUT) $(0 \cdot 1 /$ $\geq 2$ ), and smoking habit (yes/no). Pulmonary dysfunction was defined as less than $80 \%$ of percentage vital capacity (\%VC) or less than $70 \%$ of forced expiratory volume in one second percentage (FEV1.0\%).

Blood biochemical values represent results immediately prior to surgery after hospitalization. $\mathrm{mGPS}^{6}$ was scored as follows: score $2, \mathrm{CRP}>1.0 \mathrm{mg} / \mathrm{dL}$ and $\mathrm{Alb}<3.5 \mathrm{~g} / \mathrm{dL}$; score $1, \mathrm{CRP}>1.0 \mathrm{mg} / \mathrm{dL}$ or $\mathrm{Alb}<3.5 \mathrm{~g} / \mathrm{dL}$; and score 0 , CRP $\leq 1.0 \mathrm{mg} / \mathrm{dL}$ and $\mathrm{Alb} \geq 3.5 \mathrm{~g} / \mathrm{dL}$. PNI was calculated using the following formula, as proposed by Onodera at al. ${ }^{12}$ : serum albumin levels $(\mathrm{g} / \mathrm{dL}) \times 10+$ total lymphocyte count (per $\left.\mathrm{mm}^{3}\right) \times 0.005$. NLR was calculated by dividing the number of neutrophils by the number of lymphocytes $^{13}$. The CONUT Score takes the serum albumin value, total lymphocyte count, and total cholesterol value, and integrates them to evaluate nutritional status using the "CONUT score" (0-12 points) in 4 levels ${ }^{14}$. Specifically, patients with CONUT scores of $0^{-1}$ have a normal nutritional status, those with CONUT scores of 2-4 are at mild risk, those with CONUT scores of 5-8 are at moderate risk, and those with CONUT scores of 9-12 are at severe risk of malnutrition ${ }^{14}$. Blood loss, duration of surgery, and NLR beyond the 75th percentile based on the cumulative frequency distribution were considered poor.

\section{Assessment of SSIs and Complications}

SSI was diagnosed based on National Nosocomial Infection Surveillance (NNIS) System standards prescribed by the Centers for Disease Control and Prevention. Surgeons examined the wound site daily and added a description of the findings to the subject's medical records. Surveillance was conducted by a group of doctors until postoperative day 30. The authors confirmed and summarized the subject's medical records. Grade II or higher complications according to the Clavien-Dindo classification $^{15}$ were considered an incident for calculation of incidence rate.

\section{Statistical Analysis}

Statistical analyses were performed with SAS ver.9.2 (SAS Institute, Inc., Cary, NC, USA). Fisher's exact test for categorical variables and the Wilcoxon rank sum test for continuous variables were used for between-group comparisons. Univariate and multivariate logistic regression analyses were performed to identify factors associated with SSI incidence. Variables for inclusion in the multivariate analysis were selected by the stepwise procedure with all variables (stepwise forward selection with entry and stay criteria both set to $\mathrm{p}=0.25) . \mathrm{P}<0.05$ was considered statistically significant.

\section{Results}

Demographic and Clinical Characteristics of Subjects

This study involved 351 subjects (206 men 58.7\% and 145 women $41.3 \%$ ). The median age of subjects was 68 years (range: 27-92 years). Subject characteristics are shown in Table $\mathbf{1 .}$ 
Table 1 Demographic and clinical characteristics of subjects

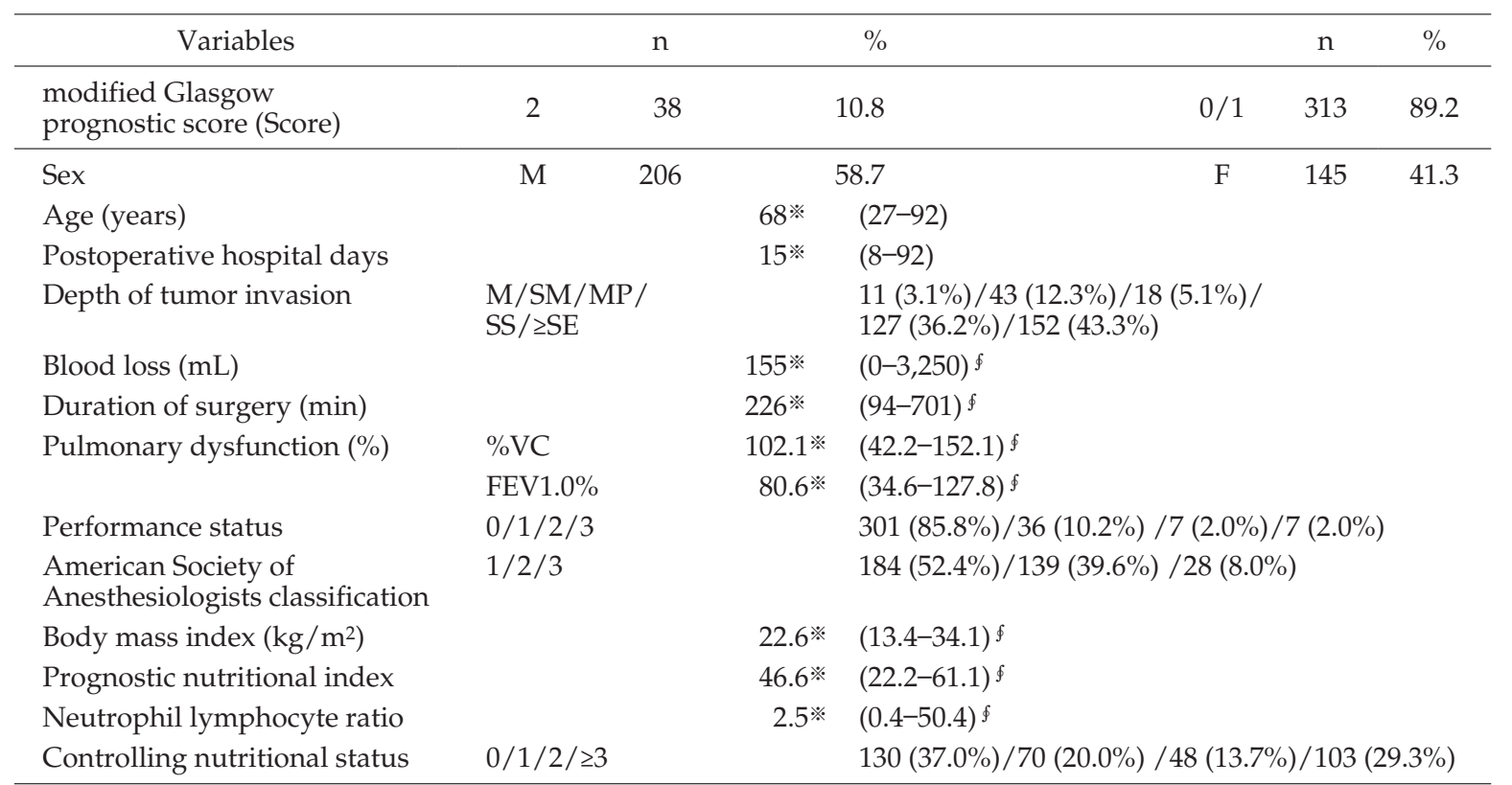

\begin{tabular}{|c|c|c|c|c|c|c|}
\hline \multicolumn{7}{|l|}{ ※median ${ }^{\S}$ range } \\
\hline & & $\mathrm{n}$ & $\%$ & & $\mathrm{n}$ & $\%$ \\
\hline Approach & laparotomy & 285 & 81.2 & laparoscopy & 66 & 18.8 \\
\hline Location & rectum & 103 & 29.3 & colon & 248 & 70.7 \\
\hline Resection of other organs & yes & 61 & 17.4 & no & 290 & 82.6 \\
\hline Colostomy & yes & 27 & 7.7 & no & 324 & 92.3 \\
\hline Timing of operation & emergency & 16 & 4.6 & elective & 335 & 95.4 \\
\hline Histology & others & 66 & 18.8 & tub1, 2 & 285 & 81.2 \\
\hline Ileus & yes & 35 & 10.0 & no & 316 & 90.0 \\
\hline Diabetes mellitus & yes & 75 & 21.4 & no & 276 & 78.6 \\
\hline Smoking habit & yes & 127 & 36.2 & no & 224 & 63.8 \\
\hline
\end{tabular}

mGPS was scored as follows: score $2, \mathrm{CRP}>1.0 \mathrm{mg} / \mathrm{dL}$ and $\mathrm{Alb}<3.5 \mathrm{~g} / \mathrm{dL}$; score $1, \mathrm{CRP}>1.0$ $\mathrm{mg} / \mathrm{dL}$; and score $0, \mathrm{CRP} \leq 1.0 \mathrm{mg} / \mathrm{dL}$ and $\mathrm{Alb} \geq 3.5 \mathrm{~g} / \mathrm{dL}$.

*median ${ }^{\S}$ range

Fisher's exact test for categorical variables and the Wilcoxon rank sum test for continuous variables were used for between-group comparisons.

\section{Incidence of SSIs}

SSIs were observed in 32 patients, with an incidence of $9.1 \%$. Superficial and deep SSIs were noted in 22 subjects $(6.3 \%)$. Twelve subjects had organ/space SSIs, including eight subjects $(2.3 \%)$ with anastomotic failure and four subjects with intra-abdominal abscess (1.1\%). Baseline characteristics by presence of SSI are shown in Table 2.

Predictive Factors for SSIs in Colorectal Cancer Surgery (Table 3 )

Univariate logistic regression analyses: In univariate logistic analysis, a significantly high incidence of SSIs was associated with mGPS (Score 2), laparotomy, resection of other organs, colostomy, excessive blood loss (>423 mL), long duration of surgery ( $>279$ minutes), pulmonary dysfunction, PNI $\leq 40$, NLR $(>4)$, and CONUT $\geq 2$.
Multivariate logistic regression analyses: In multivariate analysis with variables selected by the stepwise procedure, mGPS (Score 2) (Odds ratio $=3.55$, 95\% Confidence interval (CI) 1.30-9.56; $\mathrm{p}=0.01$ ), colostomy $(\mathrm{OR}=$ 6.56, 95\%CI 1.60-31.38; $\mathrm{p}=0.01$ ), excessive blood loss (OR $=3.20$, 95\%CI 1.23-8.42; $\mathrm{p}=0.02)$, and NLR $(>4)(\mathrm{OR}=3.24$, $95 \%$ CI 1.31-8.17; $\mathrm{p}=0.01$ ) were found to be independent risk factors.

\section{Discussion}

Since SSI not only extends hospital stay, but also increases recurrence and worsens prognosis, it is not a complication to be taken lightly ${ }^{14}$. In the present study, we examined factors that affect SSI incidence with a particular focus on cachexia, using mGPS as an index. 
Table 2 Baseline characteristics by presence of SSI

\begin{tabular}{|c|c|c|c|c|c|c|c|}
\hline Variables & & $\mathrm{n}$ & $(\%)$ & & $\mathrm{n}$ & $(\%)$ & p-value \\
\hline $\begin{array}{l}\text { modified Glasgow } \\
\text { prognostic score (Score) }\end{array}$ & 2 & 12 & 31.6 & $0 \cdot 1$ & 20 & 6.4 & $<.0001$ \\
\hline Sex & male & 19 & 9.22 & female & 13 & 9.0 & 1.00 \\
\hline Age & $\geq 75$ years & 7 & 8.1 & $<75$ & 25 & 9.4 & 0.83 \\
\hline Depth of tumor invasion & $\geq \mathrm{SS}$ & 27 & 9.7 & $\leq \mathrm{MP}$ & 5 & 7.0 & 0.65 \\
\hline Approach & laparotomy & 31 & 10.9 & laparoscopy & 1 & 1.5 & 0.02 \\
\hline Location & rectum & 13 & 12.6 & colon & 19 & 7.7 & 0.16 \\
\hline Resection of other organs & yes & 11 & 18.0 & no & 21 & 7.2 & 0.01 \\
\hline Colostomy & yes & 9 & 33.3 & no & 23 & 7.1 & 0.0001 \\
\hline Timing of operation & emergency & 2 & 12.5 & elective & 30 & 9.0 & 0.65 \\
\hline Blood loss & Large $(>423 \mathrm{~mL})$ & 19 & 22.4 & small & 13 & 4.9 & $<.0001$ \\
\hline Operating time & Long $(>279 \mathrm{~min})$ & 14 & 16.1 & short & 18 & 6.8 & 0.02 \\
\hline Histology & others & 7 & 10.6 & tub1, 2 & 25 & 8.8 & 0.64 \\
\hline Ileus & yes & 3 & 8.6 & no & 29 & 9.2 & 1.00 \\
\hline Diabetes mellitus & yes & 11 & 14.7 & no & 21 & 7.6 & 0.07 \\
\hline Pulmonary dysfunction & yes & 12 & 14.8 & no & 20 & 7.4 & 0.049 \\
\hline Performance status & $\geq 1$ & 7 & 14.0 & 0 & 25 & 8.3 & 0.19 \\
\hline $\begin{array}{l}\text { American Society of } \\
\text { Anesthesiologists } \\
\text { classification }\end{array}$ & 3 & 4 & 14.3 & $1 \cdot 2$ & 28 & 8.7 & 0.31 \\
\hline \multirow[t]{2}{*}{ Body mass index $\mathrm{kg} / \mathrm{m}^{2}$} & $<18.5$ & 2 & 7.7 & $\geq 18.5$ & 30 & 9.2 & 1.00 \\
\hline & $\geq 25$ & 5 & 6.1 & $<25$ & 27 & 10.0 & 0.38 \\
\hline Prognostic nutritional index & $\leq 40$ & 14 & 24.1 & $>40$ & 18 & 6.1 & 0.0001 \\
\hline Neutrophil lymphocyte ratio & $>4$ & 19 & 20.2 & $\leq 4$ & 13 & 5.1 & $<.0001$ \\
\hline Controlling nutritional status & $\geq 2$ & 21 & 13.9 & $0 \cdot 1$ & 11 & 5.5 & 0.008 \\
\hline Smoking habit & yes & 11 & 8.7 & no & 21 & 9.4 & 1.00 \\
\hline
\end{tabular}

Pulmonary dysfunction was defined as less than $80 \%$ of $\%$ vital capacity ( $\% \mathrm{VC}$ ) or less than $70 \%$ of forced expiratory volume in one second \% (FEV1.0\%).

mGPS was scored as follows: score $2, \mathrm{CRP}>1.0 \mathrm{mg} / \mathrm{dL}$ and $\mathrm{Alb}<3.5 \mathrm{~g} / \mathrm{dL}$; score $1, \mathrm{CRP}>1.0 \mathrm{mg} / \mathrm{dL}$; and score $0, \mathrm{CRP} \leq 1.0 \mathrm{mg} / \mathrm{dL}$ and $\mathrm{Alb} \geq 3.5 \mathrm{~g} / \mathrm{dL}$.

Blood loss, duration of surgery, and NLR were divided into 75th percentile groups based on a cumulative frequency distribution. Baseline characteristics were divided by the presence of SSI.

Fisher's exact test for categorical variables was used for between-group comparisons.

Among the few reports that have examined mGPS in the context of SSI incidence, only one report by Haruki et al. ${ }^{10}$ found GPS (Scores 1,2) to be an independent risk factor for SSIs in patients undergoing hepatic resection for colorectal liver metastases. Other reports described mGPS as a risk factor for infectious complications including RIs ${ }^{7}$. Unlike the study by Haruki et al. ${ }^{10}$, we focused only on mGPS (Score 2), but our results were similar with respect to SSI incidence.

Current discussions on the effects of cachexia on infectious complications include whether or not cases are limited to SSIs ${ }^{11}$. We thus plan to conduct a further study to examine how mGPS affects the incidence of SSIs relative to RIs.

The mechanism underlying the relationship between elevated mGPS before surgery and postoperative SSI is unknown ${ }^{7}$. However, Alb values have been reported to be correlated with lymphocyte count ${ }^{17}$ and $\mathrm{NLR}^{13}$, and to be inversely correlated with granulocyte count ${ }^{17}$ and GL ratio $^{17}$. Moreover, $\mathrm{CRP}$ values have been reported to be correlated with lymphocyte count ${ }^{18}$, NLR ${ }^{11}$, disease progression $^{18}$, and weight loss rate ${ }^{18}$. One characteristic of patients with elevated mGPS in whom the two indicators (Alb and CRP) worsened may be malnutrition and a reduction in preoperative immunocompetence, suggesting the possibility that compromised immunocompetence may influence the incidence of SSIs ${ }^{7}$.

Resolvin was recently found to reduce this inflammatory response ${ }^{19}$, effectively inhibiting signal transduction downstream of Toll-like receptors expressed in many cancer cells and normalizing abnormal neutrophil activity as well as IL-6 production. As resolvin is derived from docosahexaenoic acid (DHA) and eicosapentaenoic acid $(E P A)^{19}$, efforts have been made to improve cachexia with oral nutritional supplements (ONS) containing these components ${ }^{20}$. 
Table 3 Predictive factors for SSIs in colorectal cancer surgery

\begin{tabular}{|c|c|c|c|c|c|c|c|c|c|}
\hline \multirow[b]{2}{*}{ Variables } & & \multirow[b]{2}{*}{$\mathrm{n}$} & \multirow[b]{2}{*}{ (\%) } & \multicolumn{3}{|c|}{ Univariate logistic regression } & \multicolumn{3}{|c|}{ multivariate logistic regression } \\
\hline & & & & $\begin{array}{l}\text { crude } \\
\text { OR }\end{array}$ & $95 \% \mathrm{CI}$ & $\mathrm{p}$-value & $\begin{array}{l}\text { adjusted } \\
\text { OR }\end{array}$ & $95 \% \mathrm{CI}$ & $\mathrm{p}$-value \\
\hline $\begin{array}{l}\text { modified Glasgow } \\
\text { prognostic score (Score) }\end{array}$ & 2 & 38 & 10.8 & 6.76 & $2.93-15.28$ & 0.0001 & 3.55 & $1.30-9.56$ & 0.01 \\
\hline Sex & male & 206 & 58.7 & 1.03 & $0.50-2.21$ & 0.93 & & & \\
\hline Age & $\geq 75$ years & 86 & 24.5 & 0.85 & $0.33-1.95$ & 0.72 & 0.46 & $0.15-1.23$ & 0.14 \\
\hline Depth of tumor invasion & $\geq \mathrm{SS}$ & 279 & 79.5 & 1.44 & $0.58-4.36$ & 0.47 & 0.29 & $0.08-1.18$ & 0.07 \\
\hline Approach & laparotomy & 285 & 81.2 & 7.93 & $1.65-142.43$ & 0.04 & 6.47 & $0.94-131.66$ & 0.10 \\
\hline Location & rectum & 103 & 29.3 & 1.74 & $0.81-3.65$ & 0.15 & 0.39 & $0.10-1.29$ & 0.15 \\
\hline Resection of other organs & yes & 61 & 17.4 & 2.82 & $1.24-6.11$ & 0.01 & 2.15 & $0.79-5.71$ & 0.13 \\
\hline Colostomy & yes & 27 & 7.7 & 6.54 & $2.56-15.96$ & 0.0001 & 6.56 & $1.60-31.38$ & 0.01 \\
\hline Timing of operation & emergency & 16 & 4.6 & 1.45 & $0.22-5.53$ & 0.63 & & & \\
\hline Blood loss & large $(>423 \mathrm{~mL})$ & 85 & 24.2 & 5.60 & $2.65-12.18$ & 0.001 & 3.20 & $1.23-8.42$ & 0.02 \\
\hline Operating time & long (>279 $\mathrm{min})$ & 87 & 24.8 & 2.62 & $1.23-5.51$ & 0.01 & & & \\
\hline Histology & others & 66 & 18.8 & 1.23 & $0.47-2.85$ & 0.64 & & & \\
\hline Ileus & yes & 35 & 10.0 & 0.93 & $0.21-2.81$ & 0.91 & & & \\
\hline Diabetes mellitus & yes & 75 & 21.4 & 2.09 & $0.93-4.47$ & 0.06 & 2.22 & $0.86-5.56$ & 0.09 \\
\hline Pulmonary dysfunction & $\begin{array}{l}\% \mathrm{VC}<80 \text { or } \\
\text { FEV1.0\% } \% 70\end{array}$ & 81 & 23.1 & 2.17 & $0.99-4.61$ & 0.046 & 2.08 & $0.78-5.37$ & 0.13 \\
\hline Performance status & $\geq 1$ & 50 & 14.2 & 1.80 & $0.68-4.22$ & 0.20 & & & \\
\hline $\begin{array}{l}\text { American Society of } \\
\text { Anesthesiologists classification }\end{array}$ & 3 & 28 & 8.0 & 1.76 & $0.49-4.91$ & 0.33 & & & \\
\hline \multirow[t]{2}{*}{ Body mass index $\mathrm{kg} / \mathrm{m}^{2}$} & $<18.5$ & 26 & 7.4 & 0.82 & $0.13-2.95$ & 0.80 & & & \\
\hline & $\geq 25$ & 82 & 23.3 & 0.58 & $0.19-1.44$ & 0.28 & & & \\
\hline Prognostic nutritional index & $\leq 40$ & 58 & 16.5 & 4.86 & $2.23-10.46$ & 0.001 & & & \\
\hline Neutrophil lymphocyte ratio & $>4$ & 94 & 26.8 & 4.75 & $2.26-10.29$ & 0.001 & 3.24 & $1.31-8.17$ & 0.01 \\
\hline Controlling nutritional status & $\geq 2$ & 151 & 43.0 & 2.78 & $1.32-6.15$ & 0.008 & & & \\
\hline Smoking habit & yes & 127 & 36.2 & 0.92 & $0.41-1.93$ & 0.82 & & & \\
\hline
\end{tabular}

Univariate logistic regression analyses: In the univariate analysis, a significantly high incidence of SSIs was associated with mGPS (Score 2), laparotomy, resection of other organs, colostomy, excessive blood loss ( $>423 \mathrm{~mL}$ ), long duration of surgery ( $>279 \mathrm{~min}-$ utes), pulmonary dysfunction, $\mathrm{PNI} \leq 40, \mathrm{NLR}(>4)$, and CONUT $\geq 2$.

multivariate logistic regression analyses: In multivariate analysis with variables selected by the stepwise procedure, mGPS (Score 2) (Odds ratio=3.55 95\% Confidence interval (CI) 1.30-9.56; $\mathrm{p}=0.01$ ), colostomy ( $\mathrm{OR}=6.56$ 95\%CI 1.60-31.38; $\mathrm{p}=0.01$ ), excessive blood loss (OR=3.20 95\%CI 1.23-8.42; p=0.02), and NLR (>4) (OR=3.24 95\%CI 1.31-8.17; p=0.01) were found to be independent risk factors.

Univariate and multivariate logistic regression analyses were performed to identify factors associated with SSI incidence. Variables for inclusion in the multivariate analysis were selected by the stepwise procedure with all variables (stepwise forward selection with entry and stay criteria both set to $\mathrm{p}=0.25)$. $\mathrm{P}<0.05$ was considered statistically significant.

Preoperative administration of immune-modulating nutrients (supplemented with arginine and omega-3 fatty acids) containing DHA reportedly decreased the incidence of SSIs significantly in colon cancer patients ${ }^{20}$. ONS containing EPA have also been reported to decrease CRP values, increase Alb, and maintain weight gain two weeks after administration was initiated in patients with rectal cancer undergoing chemotherapy ${ }^{21}$. In patients with esophageal cancer, a significantly smaller portion ( $8 \%$ ) of those administered EPA had a $\geq 5 \%$ decrease in body weight compared to the control group (39\%) during the perioperative period (5 days before and 21 days after surgery $)^{22}$. However, there is no consensus with regard to reduced SSI incidence or prolonged survival, and the effects of early introduction or co-administration with antitumor therapies, such as molecular targeted therapy, are anticipated in the future ${ }^{23}$. Cachexia was once regarded as an irreversible condition, but given that a reduction in the activity of inflammation-induced substances and suppression of inflammatory cytokine production could be achieved by initiating nutrition therapy before the patient falls into an intractable state of cachexia, active multimodal therapy may prove effective $\mathrm{e}^{24}$.

NLR, which together with mGPS, was found to be an independent risk factor for the development of SSIs, is an index related to inflammatory conditions and reflects the 
balance between a tumor promoting environment and antitumor immunity ${ }^{13}$. NLR is associated with mGPS, PNI, and serum zinc levels ${ }^{25}$, and the incidences of infectious complications ${ }^{25}$ and anastomotic leakage increase at high NLR values ${ }^{26}$. In the present study as well, the incidence of SSI was higher with increased NLR values, suggesting the potential involvement of a systemic inflammatory reaction and reduced immunity, which are enhanced in the cancerous state ${ }^{26}$.

In addition to mGPS and NLR, we found excessive blood loss and colostomy, both of which are factors for which interventions are difficult preoperatively, to be independent risk factors for the development of SSIs.

Following abdominoperineal resection with colostomy, dehiscence $^{27}$ and wound infection ${ }^{28}$ are known to occur at high rates due to stool leakage or contamination of the operative field. In the present study, SSIs that frequently occurred included wound infection and dehiscence, consistent with these previous reports.

In cases for which colostomy requires a long operating time, patients with large pelvic defects may be prone to pelvic infection; this is also indicated as a reason for increased SSI incidence ${ }^{29}$. Therefore, measures should be taken against contamination, such as protecting the incision wound ${ }^{30}$. Yet, since colostomy is a patient-specific factor determined by the condition of systemic or local lesions in the patient, this too is an unavoidable factor.

Blood loss is a factor related to surgical technique and operation, and SSI incidence decreases with reduced blood loss ${ }^{31}$. Horzic et al. ${ }^{32}$ suggested that, based on the idea that preoperative anemia is a risk factor for postoperative infection in colon cancer, further bleeding during surgery may increase the risk of SSIs. Consistent with these reports, we also found blood loss to be an independent risk factor.

Blood loss can be reduced by choosing appropriate surgical instruments (e.g., ultrasonic scalpel or vessel sealing systemasuch as LigaSure ${ }^{\circledR}$ ), or selection of laparoscopic surgery over laparotomy, as it is known to cause less bleeding, although cases are limited as indications need to be assessed according to criteria such as the stage of progression ${ }^{31}$.

The present study investigated the effects of cachexia on SSI incidence using mGPS, which was found to be an independent risk factor along with colostomy, excessive blood loss, and NLR ( $>4)$. Performing early preoperative assessments of the state of cachexia and improving the condition of patients through appropriate nutrition therapy are important.

\section{Conclusion}

mGPS was found to be an independent risk factor for SSIs. Cachexia before surgery in patients with colorectal cancer might predict the incidence of SSIs.

Conflict of Interest: The authors declare no conflicts of interest.

\section{References}

1. Fearon $\mathrm{K}$, Strasser F, Anker SD, Bosaeus I, Bruera E, Fainsinger RL, Jatoi A, Loprinzi C, MacDonald N, Mantovani G, Davis M, Muscaritoli M, Ottery F, Radbruch L, Ravasco P, Walsh D, Wilcock A, Kaasa S, Baracos VE: Definition and classification of cancer cachexia: an international consensus. Lancet Oncol 2011; 12: 489-495.

2. Miki C, Kusunoki M: Perioperative nutritional management in various clinical condition: Deseases of lower digestive system. J Jpn Surg Soc 2010; 111: 368-372.

3. Miki C, Konishi N, Ojima E, Hatada T, Inoue Y, Kusunoki M: C-reactive protein as a prognostic variable that reflects uncontrolled up-regulation of the IL-1-IL-6 network system in colorectal carcinoma. Dig Dis Sci 2004; 49: 970-976.

4. Richards $\mathrm{CH}$, Roxburgh CS, MacMillan MT, Isswiasi S, Robertson EG, Guthrie GK, Horgan PG, McMillan DC: The Relationships between Body Composition and the Systemic Inflammatory Response in Patients with Primary Operable Colorectal Cancer. PLoS One 2012; 7: 1-9.

5. McMillan DC: Systemic inflammation, nutritional status and survival in patients with cancer. Curr Opin Clin Nutr Metab Care 2009; 12: 223-226.

6. McMillan DC: The systemic inflammation-based Glasgow Prognostic Score: Adecade of experience in patients with cancer. Cancer Treatment Reviews 2013; 39: 534-540.

7. Moyes LH, Leitch EF, McKee RF, Anderson JH, Horgan PG, McMillan DC: Preoperative systemic inflammation predicts postoperative infectious complications in patients undergoing curative resection for colorectal cancer. British Journal of Cancer 2009; 100: 1236-1239.

8. Mangram AJ, Horan TC, Pearson ML, Silver LC, Jarvis WR: Guideline for prevention of surgical site infection. Infect Control Hosp Epidemiol 1999; 20: 250-278.

9. Dimick JB, Chen SL, Taheri PA, Henderson WG, Khuri SF, Campbell DA: Hospital costs associated with surgical complications: a report from the private-sector National Surgical Quality Improvement Program. J Am Coll Surg 2004; 199: 531-537.

10. Haruki K, Shiba H, Fujiwara Y, Furukawa K, Wakiyama S, Ogawa M, Ishida Y, Misawa T, Yanaga K: Negative Impact of Surgical Site Infection on Long-term Outcomes after Hepatic Resection for Colorectal Liver Metastases. ANTICANCER RESEARCH 2013; 33: 1697-1704.

11. Miki C, Mohri Y, Toiyama Y, Tanaka K, Inoue Y, Uchida K: Glasgow Prognostic Score as a predictive factor differentiating surgical site infection and remote infection following colorectal cancer surgery? Br J Cancer 2009; 101: 1648-1649.

12. Onodera T, Goseki N, Kosaki G: Prognostic nutritional index in gastrointestinal surgery of malnourished cancer patients. J Jpn Surg Soc 1984; 85: 1001-1005.

13. Kubo H, Murayama Y, Arita T, Kuriu Y, Nakanishi M, Otsuji E: The prognostic value of preoperative neutrophilto-lymphocyte ratio in colorectal cancer. World J Surg 2016; 40: 2796-2802. 
14. de Ulíbarri JI, González-Madroño A, de Villar NG, González P, González B, Mancha A, Rodríguez F, Fernández G: CONUT: a tool for controlling nutritional status. First validation in a hospital population. Nutr Hosp 2005; 20: 38-45.

15. Dindo D, Demartines N, Clavien PA: Classification of Surgical Complications A New Proposal With Evaluation in a Cohort of 6336 Patients and Results of a Survey. Ann Surg 2004; 240: 205-213.

16. Tsujimoto H, Hiraki S, Sakamoto N, Yaguchi $\mathrm{Y}$, Horio T, Aikou S, Ono S, Ichikura T, Yamamoyo J, Hase K: Infectious Complications after Surgery for Gastrointestinal Malignancy Affect the Clinical Outcome. Jpn J Gastroenterol Surg 2010; 43: 704-709.

17. Shibata M, Shimura T, Nishina Y, Abe H, Yajima Y, Takenoshita S: An immune Activity-nutrition Axis related to FOLFOX4 outcome for Stage IV colorectal cancer. Biotherapy 2010; 24: 249-254.

18. Koike $Y$, Miki C, Okugawa Y, Yokoe T, Toiyama Y, Tanaka $\mathrm{K}$, Inoue $\mathrm{Y}$, Kusunoki M: Preoperative C-reactive protein as a prognostic and therapeutic marker for colorectal cancer. J Surg Oncol 2008; 98: 540-544.

19. Spite M, Norling LV, Summers L, Yang R, Cooper D, Petasis NA, Flower RJ, Perretti M, Serhan CN: Resolvin D2 is a potent regulator of leukocytes and controls microbial sepsis. Nature 2009; 461: 1287-1291.

20. Horie H, Okada M, Kojima M, Nagai H: Favorable effects of preoperative enteral immunonutrition on a surgical site infection in patients with colorectal cancer without malnutrition. Surgery Today 2006; 36: 1063-1068.

21. Hamamura K, Nakaya M, Nakagawa M, Miyazaki $M$, Miki C: A Case of Stage IV Rectal Cancer with Whom EPA Oral Nutritional Supplements Could Resolve Cachectic Condition and Promote Patient Compliance with Cancer Chemotherapy. Jpn J Cancer Chemother 2011; 38: 845-848.

22. Ryan AM, Reynolds JV, Healy L, Byrne M, Moore J, Brannelly N, Mchugh A, McCormack D, Flood P: Enteral nutrition enriched with eicosapentaenoic acid(EPA) preserves lean body mass following esophageal cancer surgery: results of a double-blinded randomized controlled trial. Ann Surg 2009; 249: 355-363.

23. Fearon KC: The 2011 ESPEN Arvid Wretlind lecture: cancer cachexia: the potential impact of translational research on patient-focused outcomes. Clin Nutr 2012; 31: 577-582.

24. Nozoe T, Matono R, Ijichi H, Ohga T, Ezaki T: Glasgow
Prognostic Score (GPS) can be a useful indicator to determine prognosis of patients with colorectal carcinoma. Int Surg 2014; 99: 512-517.

25. Sagawa M, Yagawa H, Konno S, Usuda A, Maeda H, Kim $\mathrm{K}$, Watanabe T, Yamaya E, Usui $\mathrm{T}$, Yokomizo $\mathrm{H}$, Yoshimatsu K, Shimakawa T, Katsube T, Naritaka Y: Significance of Perioperative Neutrophil Lymphocyte Ratio (NLR) in Gastric Cancer and Colon Cancer. Jpn J Cancer Chemother 2016; 43: 1243-1245.

26. Josse JM, Cleghorn MC, Ramji KM, Jiang H, Elnahas A, Jackson TD, Okrainec A, Quereshy FA: The neutrophil-tolymphocyte ratio predicts major perioperative complications in patients undergoing colorectal surgery. Colorectal Dis 2016; 18: 0236-0242.

27. Kang CY, Halabi WJ, Chaudhry OO, Nguyen V, Pigazzi A, Carmichael JC, Mills S, Stamos MJ: Risk factors for anastomotic leakage after anterior resection for rectal cancer. JAMA Surgery 2013; 148: 65-71.

28. Miki C, Konishi N, Ojima E, Hatada T, Inoue Y, Kusunoki $\mathrm{M}$ : C-reactive protein as a prognostic variable that reflects uncontrolled up-regulation of the IL-1-IL-6 network system in colorectal carcinoma. Dig Dis Sci 2004; 49: 970-976.

29. Tominaga H, Koseki M, Hatanaka N, Hurozumi K, Shimizu Y, Teramoto S, Katayama A, Yoshioka D, Ishibashi K, Han R, Aki K, Kamiike A, Inda H, Shimotaka M: Study of Surgical Site Infection in Patients Operated on for Colorectal Cancer. IRYO 2007; 61: 410-414.

30. Nishidate T, Huruhata T, Okita K, Ueki T, Akiyama E, Meguro M, Mizuguchi T, Hirata K: Risk factor of surgical site infection (SSI) in rectal surgery. Infect 2014; 11: 307310.

31. Horiuchi T, Tanisima H, Miyagawa $Y$, Uemura R, Tamagawa K, Nakai H, Shouno Y, Tubakibara H, Inoue M, Tabuse K: Preventive measures against surgical site infections (SSIs) during endoscopic surgery based on the SSI risk factors in colorectal cancer patients. J Jpn Soc Surg Infect 2007; 4: 313-318.

32. Horzic M, Kopljar M: Postoperative infections in colorectal cancer patients. Hepatogastroenterology 2005; 52: 101104.

(Received, March 7, 2017)

(Accepted, August 8, 2017) 